УДК $332.1,330.322$

10.17213/2075-2067-2019-4-44-61

\title{
ТЕХНОЛОГИЧЕСКАЯ ИНДУСТРИАЛИЗАЦИЯ: РЕГИОНАЛЬНАЯ СПЕЦИФИКА
}

\author{
(C) 2019 г. O. С. Сухарев*, E. Н. Ворончихина**
}

\section{*Институт проблем рынка РАН, г. Москва \\ **Пермский государственный национальный исследовательский университет}

Целью исследования является определение стратегий технологического развития в регионах-лидерах и регионах-аутсайдерах рейтинга инноваџионного развития регионов России. В качестве метода исследования используется структурный анализ, позволяющий выделить режимы технологического обновления в зависимости от реакции экономики на увеличение инвестиций в новые и старые технологии. В ходе исследования подтверждено, что инвестиции в новые и старые технологии оказывают различное влияние на общий технологический уровень, в связи с чем реализуются индивидуальные для каждого региона стратегии технологического развития. Тем самым сложившийся тип стратегии определяется чувствительностью уровня технологичности к инвестициям в новые и старые технологии. Проводится оценка уровня индустриализации для одного из рассмотренной совокупности региона по общему и специальному критериям индустриализачии с учетом разделения технологий на старые и новые и выделения двух секторов экономики региона - обрабатывающего и трансакиионно-сырьевого. Используемые критерии представляют инструмент диагностики прочесса региональной индустриализачии, позволяющий выделить специфические условия данного прочесса и конкретизировать меры региональной экономической политики. Еще одним результатом исследования является спецификаџия стратегий технологического развития отобранных для рассмотрения регионов России.

Ключевые слова: регионы; новые и старые технологии; технологичность; индустриализация; общий и специиальный критерии индустриализации.

The purpose of the research is to determine the strategies of technological development in the regions-leaders and regions-outsiders of the rating of innovative development of the Russian regions. The research method is the structural analysis, which makes it possible to single out modes of technological renewal depending on the response of the economy to an increase in investment in new and old technologies. The research confirmed that investments in new and old technologies have the different impact on the technological level. Therefore technological development strategies are implemented for each region. Thus, the established type of strategy is determined by the sensitivity of the technological level to investments in new and old technologies. An assessment of the level of industrialization is carried out for one of the considered region according to the general and special criteria of industrialization, taking into account the division of technologies into old and new and the separation of two sectors of the regional economy manufacturing and raw materials. The criteria used represent the tool for diagnosing the process of regional industrialization, which allows to identify the specific conditions of this process and specify the measures of regional economic policy. Another result of the study is the specification of technological development strategies of Russian regions. 
Key words: regions; new and old technologies; technological level; industrialization; general and special criteria of industrialization.

\section{Введение}

Проблемы эволюции региональных экономических систем могут быть описаны на основе эволюционной теории [2, 9], которая позволяет принять во внимание технологические факторы развития. В настоящем исследовании предпримем анализ уровня технологичности отдельных регионов России, покажем возможности мониторинга динамики процесса технологической индустриализации на основе двух основных критериев (общего и специального [3-8]). Первый критерий отвечает так называемой общей индустриализации, второй - специальной или технологической индустриализации. Определение стратегии технологического развития для конкретного региона важно с точки зрения обоснования мер региональной поли- тики его индустриального развития [12-13]. Каждый из рассмотренных регионов имеет свою специфику технологического развития, что подчеркивается проведенным мониторингом и расчетом общего уровня технологичности, а также выявленной связью между технологичностью и динамикой инвестиций в новые и старые технологии ${ }^{1}$.

\section{1. Типы индустриализации и критерии ее мониторинга}

Эффект снижения доли обрабатывающих производств и увеличения сервисной экономики получил наименование деиндустриализации. Он закономерно происходил в развитых странах за счет повышения общей технологичности и конкретно - технологичности обрабатывающего сектора. Поэтому,
1) Общая

(рост доли индустрии)

\section{ИНДУСТРИАЛИЗАЦИЯ}

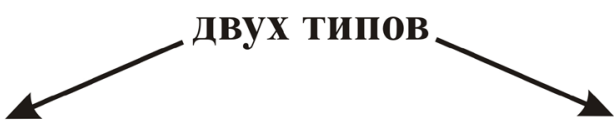

2) Специальная

(рост технологичности)

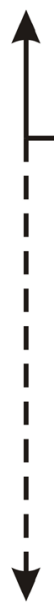

3) Десервисный процесс
Обрабатывающий сектор (повышающийся вклад в темп роста)

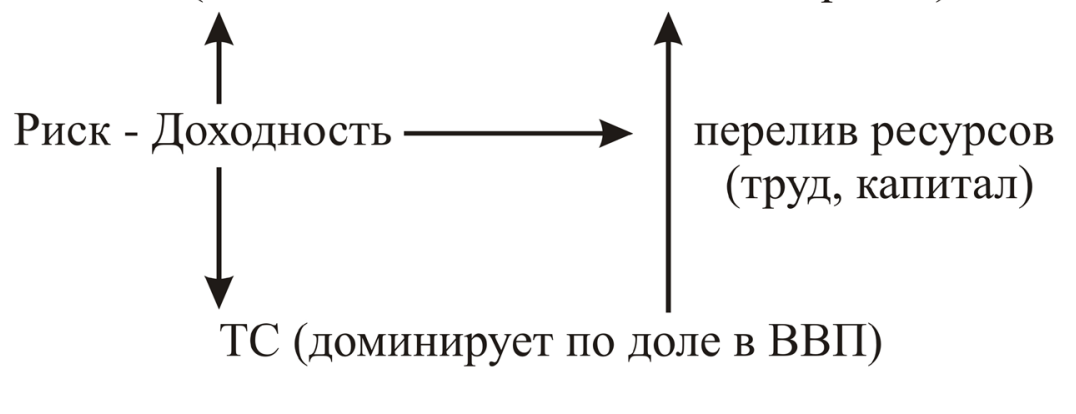

4) Сервисный процесс

\section{Структурная политика}

Рис. 1. Два типа индустриализации и структурная политика (ТС - трансакционно-сырьевой сектор)

1 Инвестиции в новые технологии - это инвестиции в созданные передовые технологии, инвестиции в старые технологии - это инвестиции в уже используемые технологии (Росстат даёт данные о величинах инвестирования новых и старых технологий как и о числе занятых в соответствующих производствах). 
если по доле в ВВП наблюдалась деиндустриализация, то по изменению уровня технологичности - «технологическая индустриализация». Тем самым можно говорить о наличии двух основных моделей индустриализации - общей (по доле индустрии в ВВП) и технологической (по изменению технологичности индустриального сектора), которую можно обозначить как специальную (рис. 1).

Если ставится задача индустриализации, даже второго типа (технологической), то на ее реализацию требуется получить необходимый ресурс (труд и капитал). Это изменяет структуру секторов, соотношение риска и доходности, что формирует иную структуру и влияет на вклад в темп роста экономики. Механизм этого изменения показан на рисунке 1 (справа), где динамика по общей модели индустриализации приводит к «десервисной» экономике (уменьшению сервисного сектора $\left.^{2}\right)$. Однако процесс технологической индустриализации, который также нуждается в ресурсах, укрепляет позиции сервисного сектора.

В работе автора [6] «Теория реструктуризации экономики» дается подробный вывод критериев индустриализации. Здесь ограничимся лишь итоговыми соотношениями, сведя сам критерий, в отличие от полученного в ранних статьях и указанной монографии, к неравенству относительно единицы. В этом случае придется учитывать знак знаменателя левой части неравенства при определении индустриализации или деиндустриализации.

Представим экономику региона, состоящую из обрабатывающего и сырьевого секторов, причем каждый сектор характеризуется некоторой долей в ВРП. Тогда разница этих долей составляет «структурный разрыв» для данной экономики, который выглядит следующим образом: $X=d_{\mathrm{II}}-d_{\mathrm{I}}$, где $d_{\text {II }}$ - доля сырьевого сектора, $d_{\text {I }}$ - доля обрабатывающего сектора. Обозначим соотношение долей: $K=d_{\mathrm{I}} / d_{\mathrm{II}}$. Тогда общий критерий индустриализации соответствует условию: $d X / d t<0$. Примем, что $Y_{\mathrm{I}}, Y_{\mathrm{II}}-$ объем продукта каждого сектора; $N$ - общее число занятых в экономике региона; $i_{\text {I }}$, $i_{\mathrm{II}}$ - масштабированная выработка, определяемая соотношением продукта сектора к общему числу занятых в экономике региона. Получим следующие соотношения:

$$
\begin{gathered}
X=(1-K) d_{\mathrm{II}}, \\
d_{\mathrm{I}}=Y_{\mathrm{I}} / Y, d_{\mathrm{II}}=Y_{\mathrm{II}} / Y, \\
i_{\mathrm{I}}=Y_{\mathrm{I}} / N, i_{\mathrm{II}}=Y_{\mathrm{II}} / N(N-\text { число занятых }), \\
K=i_{\mathrm{I}} / i_{\mathrm{II}}
\end{gathered}
$$

Условие индустриализации и деиндустриализации примет вид [3]:

$d X / d t<0$ - условие индустриализации, $d X / d t>0$ - условие деиндустриализации.

Учтя, что [1/d $\left.d_{\mathrm{II}}\right] d d_{\mathrm{II}} / d t=s$ - относительное приращение доли сырьевого сектора и $\left[\left(1 / i_{\mathrm{I}}\right) d i_{\mathrm{I}} / d t-\left(1 / i_{\mathrm{II}}\right) d i_{\mathrm{II}} / d t\right]=\lambda-$ разница относительных приращений масштаба производства обрабатывающего и добывающего секторов, получим общий критерий индустриализации:

$$
K /[s /(\lambda+s)]>1 \text { при } s /(\lambda+s)>0,
$$

причем, если $s /(\lambda+s)<0$, то критерий принимает вид:

$$
K /[s /(\lambda+s)]<1,
$$

поэтому знак соотношения $s /(\lambda+s)$ становится важным при расчете критерия индустриализации.

Если ввести структуру технологий, то специальный критерий индустриализации получается следующим образом.

Пусть объем производства на старых и новых технологиях $O_{\mathrm{I}}, N_{\mathrm{I}}$ для первого сектора и $O_{\text {II }}, N_{\text {II }}$ - для второго сектора, так что $Y_{\text {I }}=O_{\text {I }}+N_{\text {I }}$ и $Y_{\text {II }}=O_{\text {II }}+N_{\text {II }}$, тогда $K=\left(O_{\mathrm{I}}+N_{\mathrm{I}}\right) /\left(O_{\mathrm{II}}+N_{\mathrm{II}}\right)$, и, учтя, что $\alpha=O_{\text {I }} / O_{\text {II }}$ и $\gamma_{\text {I }}=N_{\text {II }} / O_{\text {I }}$,

получаем [3]:

$$
\gamma_{\mathrm{II}}=N_{\mathrm{II}} / O_{\mathrm{II}}
$$

$$
\begin{gathered}
s(1-K)<d K / d t \\
d K / d t=K[(1 / \alpha) d \alpha / d t+\mu(t)],
\end{gathered}
$$

где:

$$
\mu(t)=\frac{1}{1+\gamma_{1}} \frac{d \gamma_{1}}{d t}-\frac{1}{1+\gamma_{2}} \frac{d \gamma_{2}}{d t}
$$

- разница взвешенных изменений долей производства на новых технологиях в каждом секторе [3].

Таким образом, с учетом технологической структуры производства специальный критерий индустриализации имеет вид:

$$
\frac{K}{s /\left[\frac{1}{\alpha} \frac{d \alpha}{d t}+\mu+s\right]}>1 .
$$

2 Такой процесс в развитых странах не обнаруживается, однако он теоретически возможен. 
Подобно общему критерию аналогом $\lambda$ выступает сумма $(1 / \alpha) d \alpha / d t+\mu$.

В специальном критерии также важно учитывать знак знаменателя левой части неравенства. Если $s /[(1 / \alpha) d \alpha / d t+\mu+s]>0$, то критерий остается больше единицы, если $s /[(1 / \alpha) d \alpha / d t+\mu+s]<0$, то левая часть критерия должна быть меньше единицы, чтобы отражать условие индустриализации экономики.

В индустриальной системе старые технологии активнее применяются в обрабатывающем секторе, чем в сырьевом. То же относится к развертыванию новых технологий, хотя сырьевой сектор также имеет большую потребность в новых технологиях, что будет характеризовать процесс индустриализации. Однако интенсивность применения таких технологий в обрабатывающем секторе должна быть выше.

Анализ факторов, влияющих на производство в каждом секторе, а также на масштабированную производительность, позволит установить причины деиндустриализации региональной экономики по общему критерию. Оценка факторов, влияющих на применение новых и старых технологий (например, влияние инвестиций в старые и новые технологии), а также институциональных ограничений приведет к выявлению причин соблюдения или не соблюдения специального критерия индустриализации.

Однако применение данных критериев при мониторинге регионального развития, даже без проведения факторного анализа и выяснения чувствительности к инструментам промышленной политики, позволит осуществить диагностику состояния региональной системы, определить динамику процесса индустриализации и деиндустриализации с вытекающими возможными изменениями в области определения целей экономической политики, что составляет важнейшее направление в области стратегического планирования в регионах.

Непредсказуемое или ситуационное изменение специализации региональной экономики может не согласовываться с отдаленными ориентирами развития, причем наиболее важные, с точки зрения наращения ресурсного потенциала, возможности могут оказаться упущенными. Конечно, вопрос сохранять или не сохранять специализацию, углублять и насколько индустриализацию, зависит не от представленных критериев, а скорее, от ресурсных возможностей региона, а также условий кооперации с другими регионами, спроса на создаваемую продукцию.

Системные параметры экономики будут сильно влиять на этот процесс, включая и расположение данного региона, которое может оказаться более или менее выгодным с точки зрения развития индустрии и применения новых технологий относительно иных регионов. В связи с этим региональная и общая экономическая политика в стране, факторы, воздействующие на перелив ресурсов между видами деятельности, регионами, а также внутри региональной системы, являются детерминантами траектории развития. Выбор мер промышленной политики должен исходить из диагностики (мониторинга) состояния индустриальной системы (оценки уровня индустриализации) с тем, чтобы привести ее к желаемому состоянию. Тем самым принимаемые решения зависят от характеристики такого желаемого состояния и понимания мер, которые к нему могут или должны привести. С другой стороны, набор государственных мер воздействия на федеральном и региональном уровне также ограничен не только законами о промышленной политике и стратегическом планировании, но и другими уже введенными институтами (включая институты развития).

Под технологичностью ${ }^{3}$ понимается способность производства производить тот же объем изделий с меньшими затратами различных ресурсов за счет того, что применяются новые технологии, заменяющие устаревающие, менее эффективные. Тем самым процесс технологического обновления - это процесс повышения эффективности производственного процесса. Связывая процесс деиндустриализации с новой экономикой, «информационной», необходимо принимать во внимание, что возникновение такой системы - это не толь-

3 В данной статье технологичность определяется авторами как отношение объёма производства на новых технологиях к объёму производства на старых технологиях. Под объемом производства на новых технологиях понимается объем инновационной продукции. Объём производства на старых технологиях определяется вычитанием из общего объёма производства объема инновационной продукции. 
ко результат развития производства и техники, но главным образом науки и образования, которые связаны с решением различных производственных задач [3-7].

Проведем сравнительный анализ регионов России на предмет установления моделей технологической индустриализации. Дадим типизацию регионов в границах матрицы, представленной в таблице 1, обозначив четыре базовые стратегии технологического развития.

Таблица 1 позволяет осуществить ранжирование регионов по типу имеющейся технологической стратегии. Она показывает модели технологической индустриализации, исходя из роста расходов на новые и старые технологии. Чувствительность общего уровня технологичности к таким инвестициям может быть разная. Так, рост инвестиций в новые технологии может повышать общий технологический уровень системы, при этом инвестиции в старые технологии - снижать этот уровень (модель «технологического лидерства»). Модель «технологического рывка» предполагает такое функционирование системы, когда рост инвестиций и в новые, и в старые технологии приводит к увеличению технологического уровня.

Общее снижение технологического уровня может осуществляться за счет роста расходов на старые или новые технологии. Например, рост расходов на новые технологии может незначительно повышать технологический уровень, а на старые технологии его сильно снижать, так что общий эффект будет состоять в снижении технологического уровня. Следовательно, снижение технологического уровня региональной экономики не означает отсутствия в ней инноваций, новых проектов и технологий.

Таким образом, реализация региональной политики предусматривает диагностику типа (стратегии) технологического развития региона с тем чтобы определить и обосновать направления управленческих воздействий.

2. Региональные аспекты технологической индустриализации России

Предпримем сравнительное исследование регионов России на предмет установле-

\section{Четыре основные модели технологической индустриализации ${ }^{4}$}

Таблица 1

\begin{tabular}{|c|c|c|}
\hline $\begin{array}{c}\text { Технологический } \\
\text { уровень }\end{array}$ & $\begin{array}{c}\text { Рост технологичности } \\
\text { (при росте расходов) }\end{array}$ & $\begin{array}{c}\text { Снижение технологичности } \\
\text { (при росте расходов) }\end{array}$ \\
\hline $\begin{array}{l}\text { Выше среднего } \\
\text { по стране }\end{array}$ & $\begin{array}{l}\text { Модель «технологического ли- } \\
\text { дерства». Рост расходов на новые } \\
\text { технологии увеличивает техно- } \\
\text { логичность системы, рост рас- } \\
\text { ходов на старые - снижает ее. }\end{array}$ & $\begin{array}{l}\text { Модель «сдачи позиций», конку- } \\
\text { рентного поражения. В силу низ- } \\
\text { кой эффективности технологий при } \\
\text { росте расходов на новые техноло- } \\
\text { гии технологичность системы сни- } \\
\text { жается. Расходы на старые техноло- } \\
\text { гии ведут к росту технологичности. }\end{array}$ \\
\hline $\begin{array}{l}\text { Ниже среднего } \\
\text { по стране }\end{array}$ & $\begin{array}{l}\text { Модель «технологического рыв- } \\
\text { ка» или «догоняющего (опере- } \\
\text { жающего) развития», сокраще- } \\
\text { ния технологического отстава- } \\
\text { ния. Расходы на новые и ста- } \\
\text { рые технологии повышают об- } \\
\text { щую технологичность системы. }\end{array}$ & $\begin{array}{l}\text { Модель «технологической деграда- } \\
\text { ции», технологической зависимос- } \\
\text { ти. При низком уровне техноло- } \\
\text { гичности рост расходов на новые } \\
\text { и старые технологии не приво- } \\
\text { дит к повышению технологич- } \\
\text { ности, система не восприимчива } \\
\text { к технологическому обновлению. }\end{array}$ \\
\hline
\end{tabular}

4 Под затратами на новые технологии авторы понимают затраты на технологические инновации (In), затраты на старые технологии определяются как разница между инвестициями в основной капитал и затратами на технологические инновации (Is). 
ния стратегий их технологического развития с акцентом на инвестиции в новые технологии и их изменение. Это позволит определить специфические особенности развития региональной экономической политики.

Отбор регионов произведем, исходя из рейтинга инновационного развития регионов России по итогам 2018 года ${ }^{5}$. Выберем 6 лучших и 5 худших регионов России по данному рейтингу. К ним относятся: Республика Татарстан, Томская область, Московская область, Новосибирская область, Калужская область, Нижегородская область; Республика Дагестан, Республика Тыва, Ненецкий автономный округ, Чукотский автономный округ.

На рисунках, представленных ниже, продемонстрирована зависимость общего уровня технологичности от затрат на новые технологии (рис. 2-7 - для регионов - лидеров инновационного рейтинга России, рис. 8-11 - для регионов - аутсайдеров данного рейтинга).

Лидером рейтинга инновационных регионов России, составленного по итогам 2018 года, является Республика Татарстан. Зависимость уровня технологичности от затрат на новые технологии в регионе показана на рис. 2. Важно отметить, что уровень технологичности в Татарстане наибольший среди всех регионов России - в отдельные годы (2013-2014 гг.) превышает 0,25, что выше общероссийского уровня более чем в 2,5 раза.

Кроме того, затраты на технологические инновации в Татарстане по величине зани-
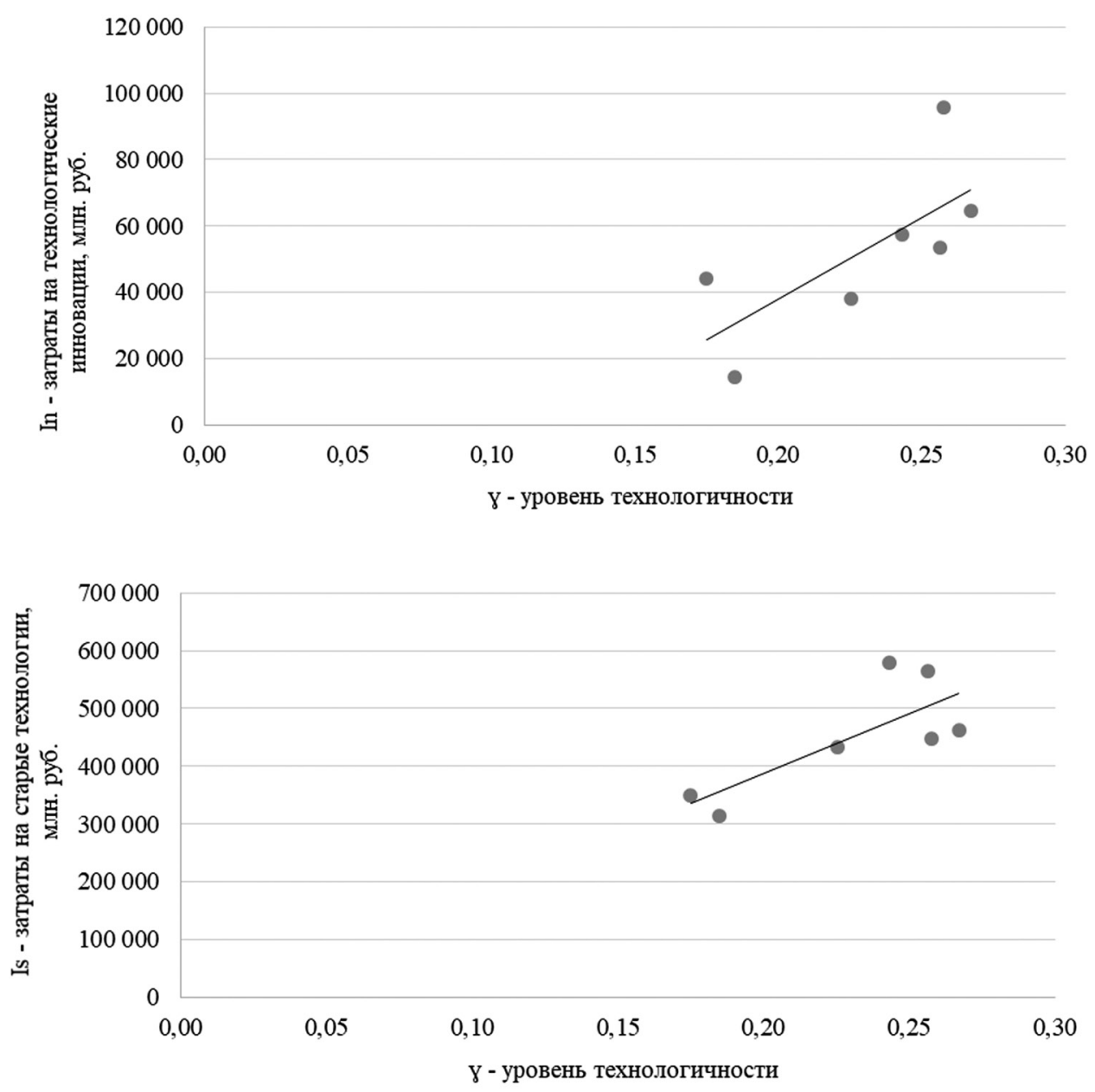

Рис. 2. Зависимость уровня технологичности от затрат

на новые (вверху) и старые (внизу) технологии в Республике Татарстан, 2010-2016 гг.

5 Рейтинг инновационных регионов России для целей мониторинга и управления был разработан Ассоциацией инновационных регионов России в 2012 году совместно с Министерством экономического развития Российской Федерации при участии представителей региональных администраций и ведущих экспертов страны. 

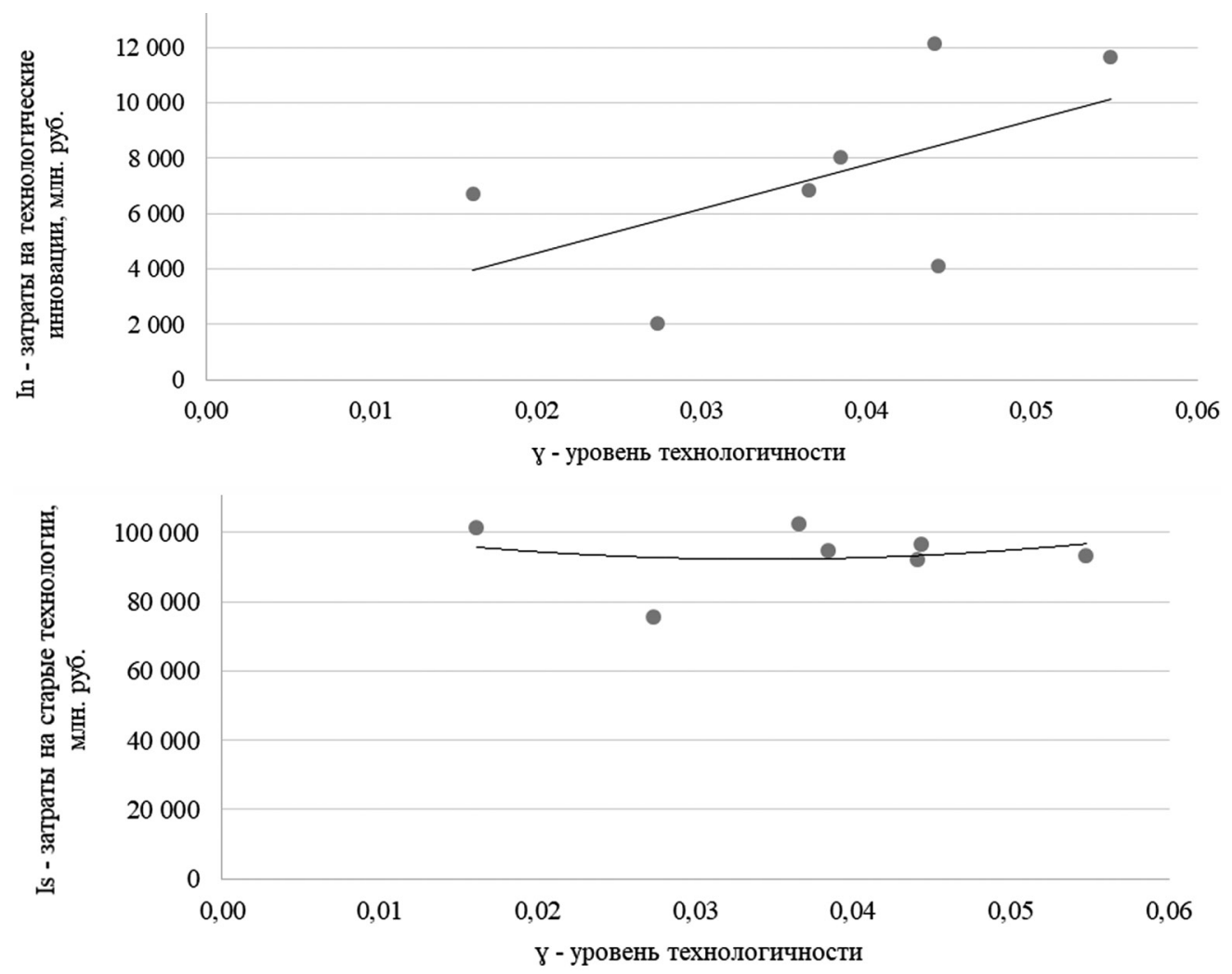

Рис. 3. Зависимость уровня технологичности от затрат на новые (вверху) и старые (внизу) технологии в Томской области, 2010-2016 гг.
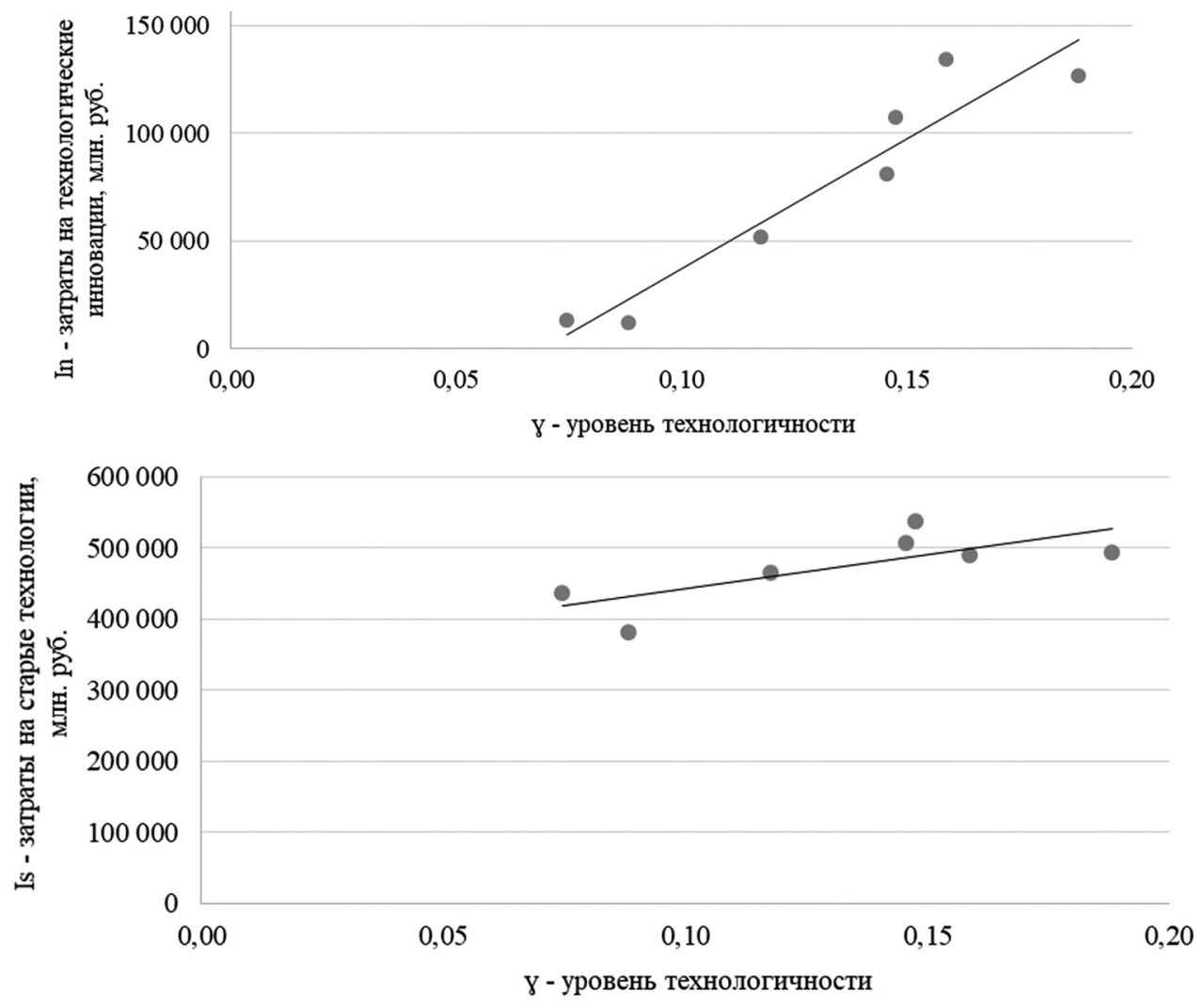

Рис. 4. Зависимость уровня технологичности от затрат на новые (вверху) и старые (внизу) технологии в Московской области, 2010-2016 гг. 
мают 2-е место в России (после Московской области) и составляют почти 4,5\% от общих затрат регионов в 2016 году. Исходя из рис. 2 видно, что рост затрат на новые и старые технологии сопровождается ростом уровня технологичности системы.

Томская область (рис. 3) характеризуется невысоким уровнем технологичности, ниже общероссийского, причем тенденция сохраняется на всем промежутке времени. Наибольшее значение технологичности в Томской области отмечается в 2015 г. и составляет 0,55 при общероссийском уровне в 0,093. Для Томской области характерна положительная связь между уровнем технологичности и затратами на новые технологии, в то время как между технологичностью и затратами на старые технологии обнаруживается небольшая отрицательная связь.

Высокий уровень технологичности системы отмечается в Московской области (рис. 4) и по итогам 2016 г. составляет 0,188, что является 3-й позицией среди регионов России по данному показателю после Татарстана и Нижегородской области. Важно отметить, что скачок технологичности в Московской области произошел в 2012 г. и далее наблюдается стабильная положительная динамика. Резкий роста показателя в 2012 г. объясняется почти четырехкратным ростом затрат на технологические инновации.

Также Московская область занимает уверенную лидирующую позицию по величине таких затрат, доля которых в общих затратах на технологические инновации России составляет 9,9\%, и опережает Татарстан по данной величине в 2,2 раза. В Московской области, как и в Республике Татарстан, рост затрат на новые и старые технологии способствует росту технологичности.

Аналогичная тенденция отмечается в Новосибирской области (рис. 5), которая также имеет уровень технологичности выше общероссийского и в 2016 г. - 0,107. Несмотря на относительно других регионов высокий уровень технологичности, затраты на технологические инновации Новосибирской области наименьшие среди регионовлидеров инновационного рейтинга России и составляют лишь $0,57 \%$ от всех затрат на технологические инновации российских регионов.
В Калужской области (рис. 6) не обнаруживается четко выраженной динамики зависимости уровня технологичности от затрат на новые технологии. Отметим, что уровень технологичности в регионе наименьший среди топ-6 регионов-лидеров и не превышает 0,048 (2011-2012 гг.), причем с этого периода уровень технологичности неуклонно снижается при росте затрат на технологические инновации. В целом в области меньшего уровня технологичности $(0,02-0,04)$ отмечается положительная связь между технологичностью и затратами на технологические инновации, а в области более высокой технологичности (0,04-0,05) - отрицательная связь, т.е. рост затрат на технологические инновации сопровождается снижением технологичности.

Нижегородская область (рис. 7) характеризуется относительно высоким уровнем технологичности среди всех регионов России, занимая при этом в среднем 2-е место после Татарстана по данному показателю, а в некоторые годы $(2011,2014$ гг.) даже превышает технологический уровень Татарстана. Также в Нижегородской области высокие затраты на технологические инновации (после Московской области и Татарстана) и составляют 4,2\% от общих затрат на технологические инновации России. Для региона характерна модель технологической индустриализации, при которой повышение затрат на новые и старые технологии обеспечивает рост уровня технологичности.

Далее на рис. 8-11 представлены зависимости уровня технологичности от затрат на новые технологии в слабо инновационных регионах России: Чукотском и Ненецком автономных округах, Республиках Тыва и Дагестан. В данных регионах в целом отмечается обратная динамика, т.е. небольшой рост затрат на технологические инновации приводит к снижению уровня технологичности системы. Для Чукотского автономного округа характерна ситуация, при которой рост затрат на технологические инновации приводит к снижению технологичности, а рост затрат на старые технологии, напротив, повышает технологичность.

В Ненецком автономном округе, Республиках Тыва и Дагестан в целом рост как новых, так и старых технологий приводит к снижению уровня технологичности системы. 

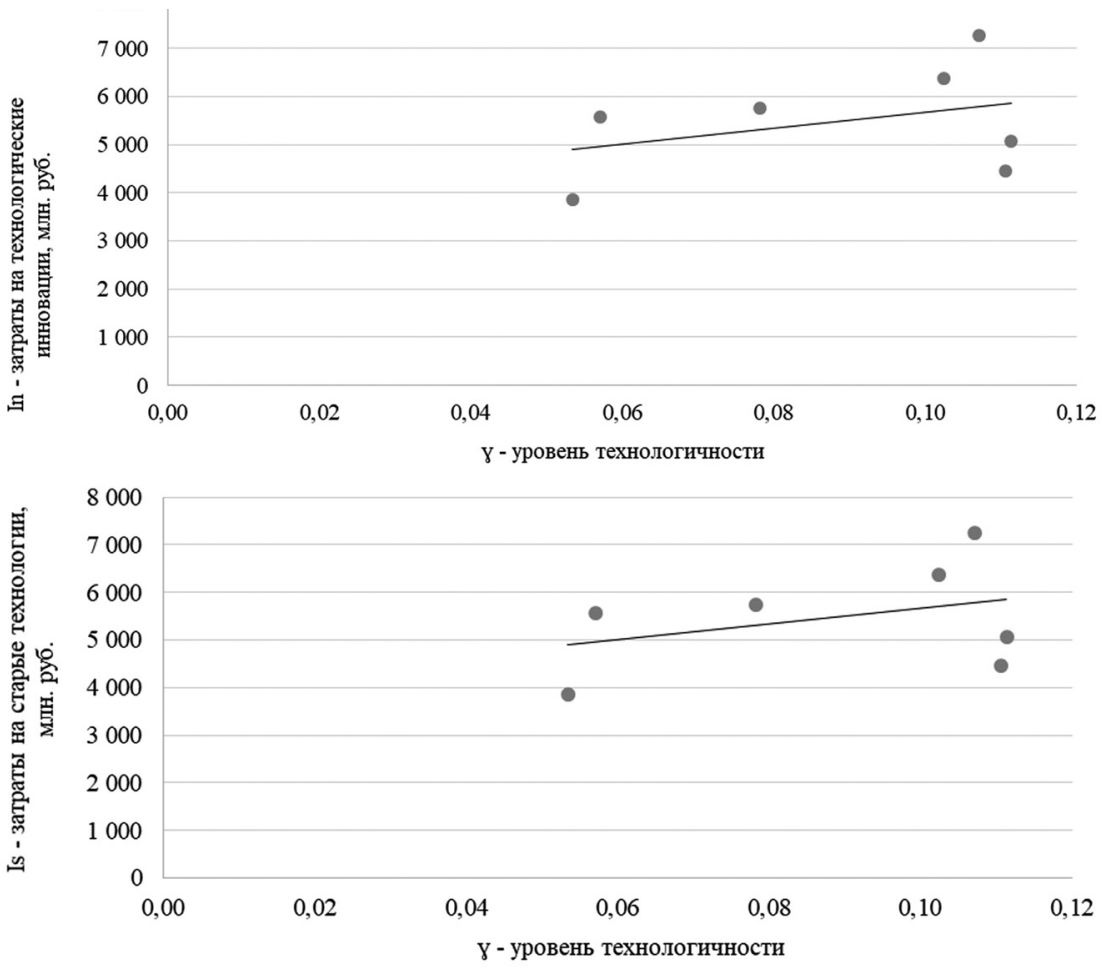

Рис. 5. Зависимость уровня технологичности от затрат на новые (вверху) и старые (внизу) технологии в Новосибирской области, 2010-2016 гг.
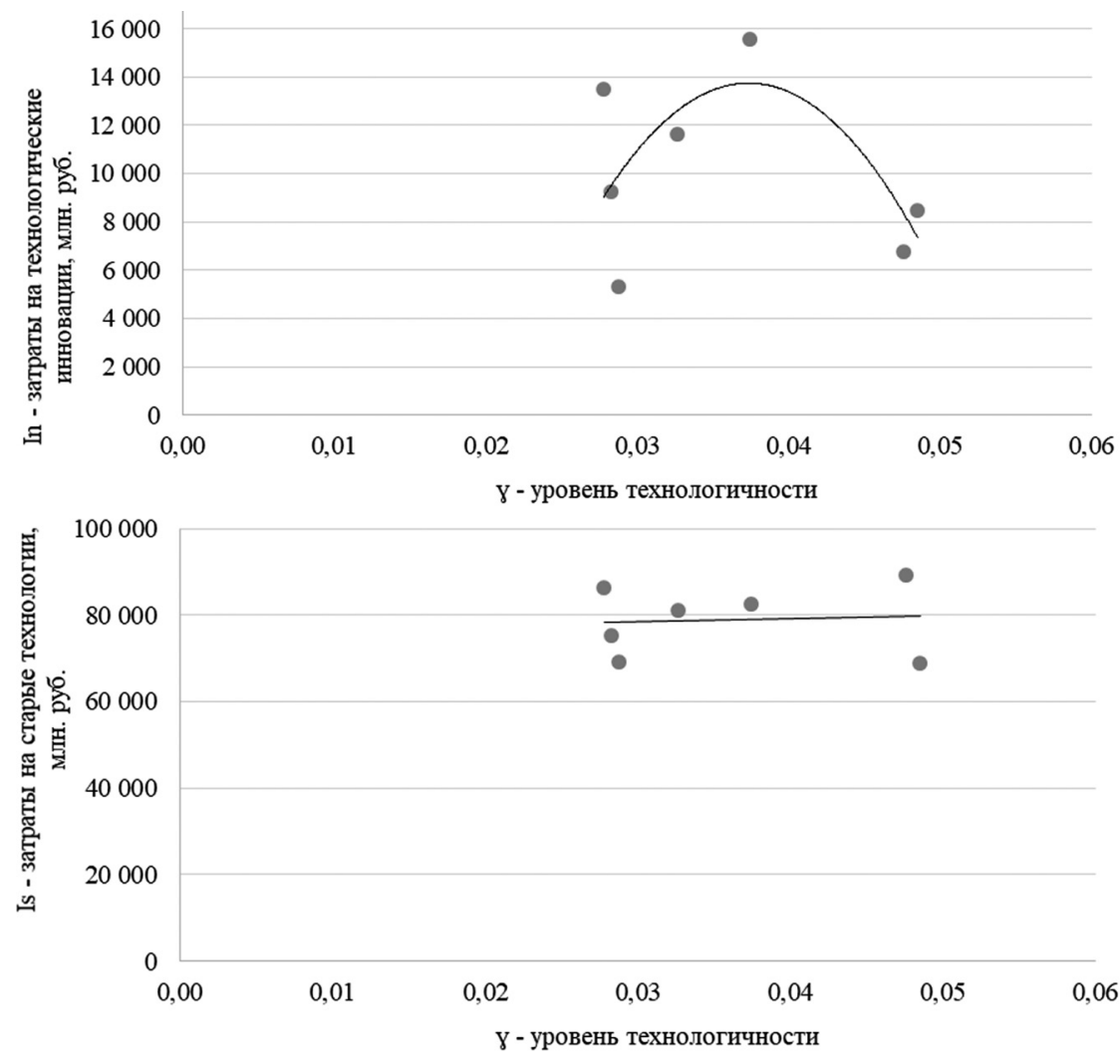

Рис. 6. Зависимость уровня технологичности от затрат на новые (вверху) и старые (внизу) технологии в Калужской области, 2010-2016 гг. 

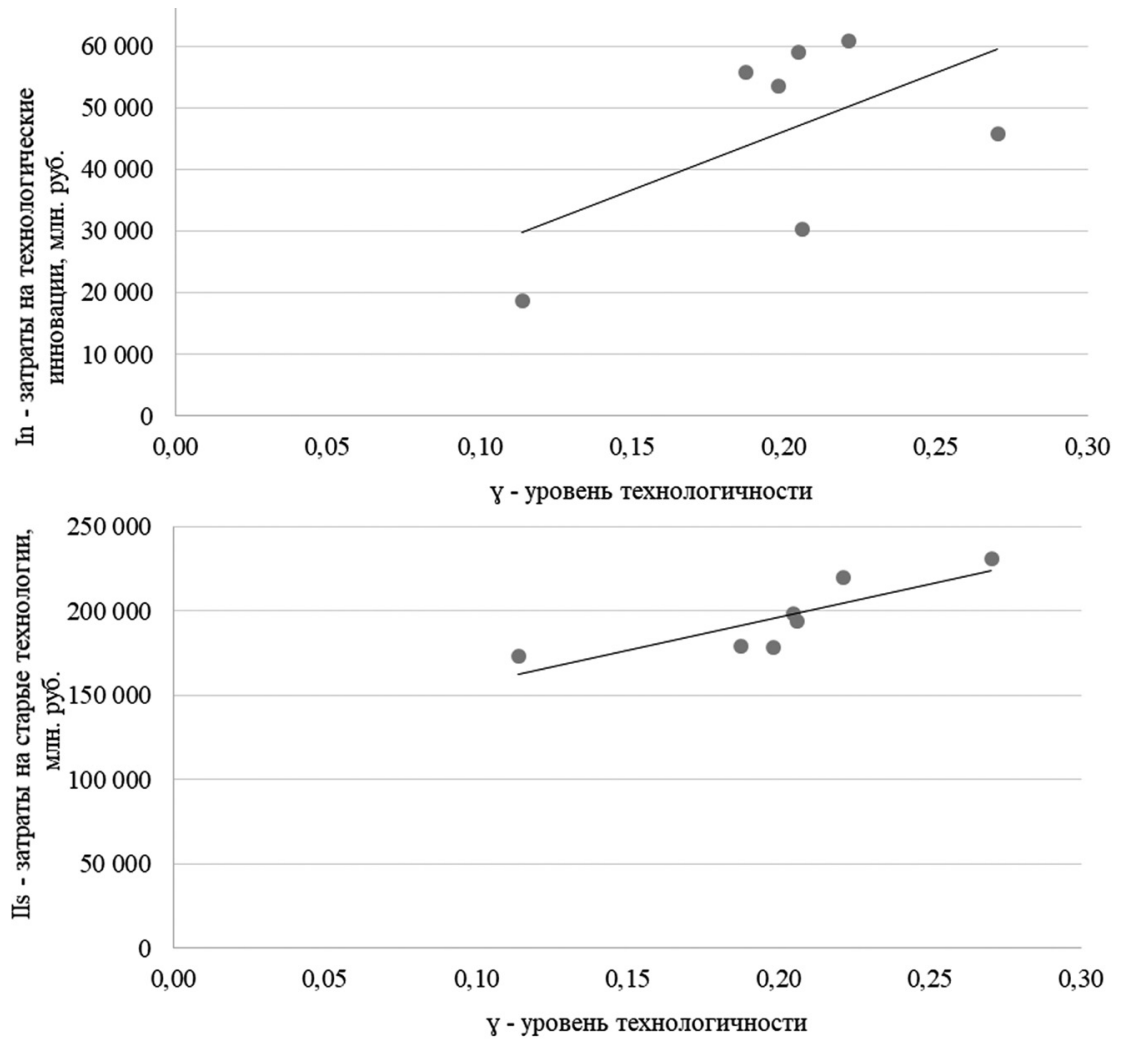

Рис. 7. Зависимость уровня технологичности от затрат на новые (вверху) и старые (внизу) технологии в Нижегородской области, 2010-2016 гг.
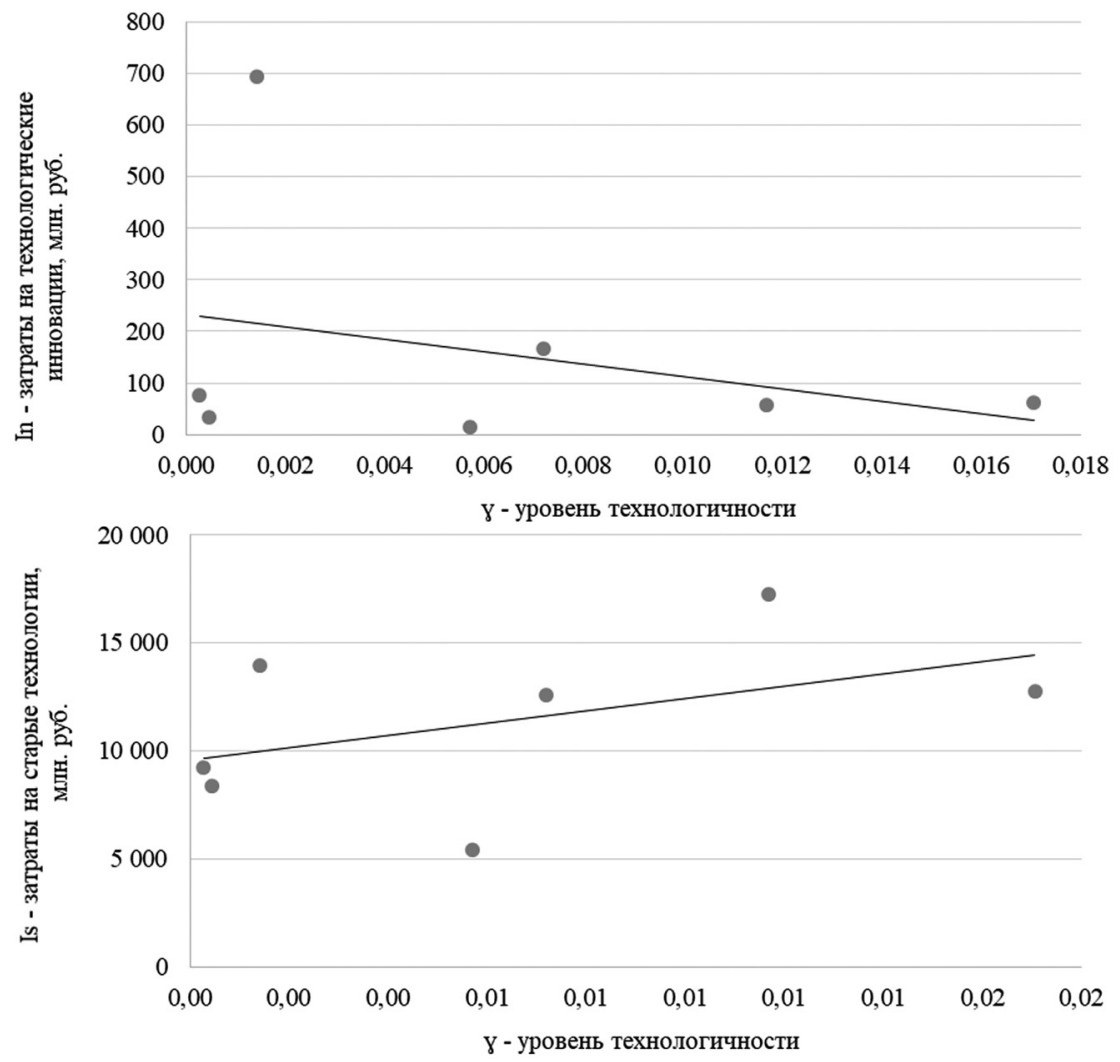

Рис. 8. Зависимость уровня технологичности от затрат на новые (вверху) и старые (внизу) технологии в Чукотском автономном округе, 2010-2016 гг. 

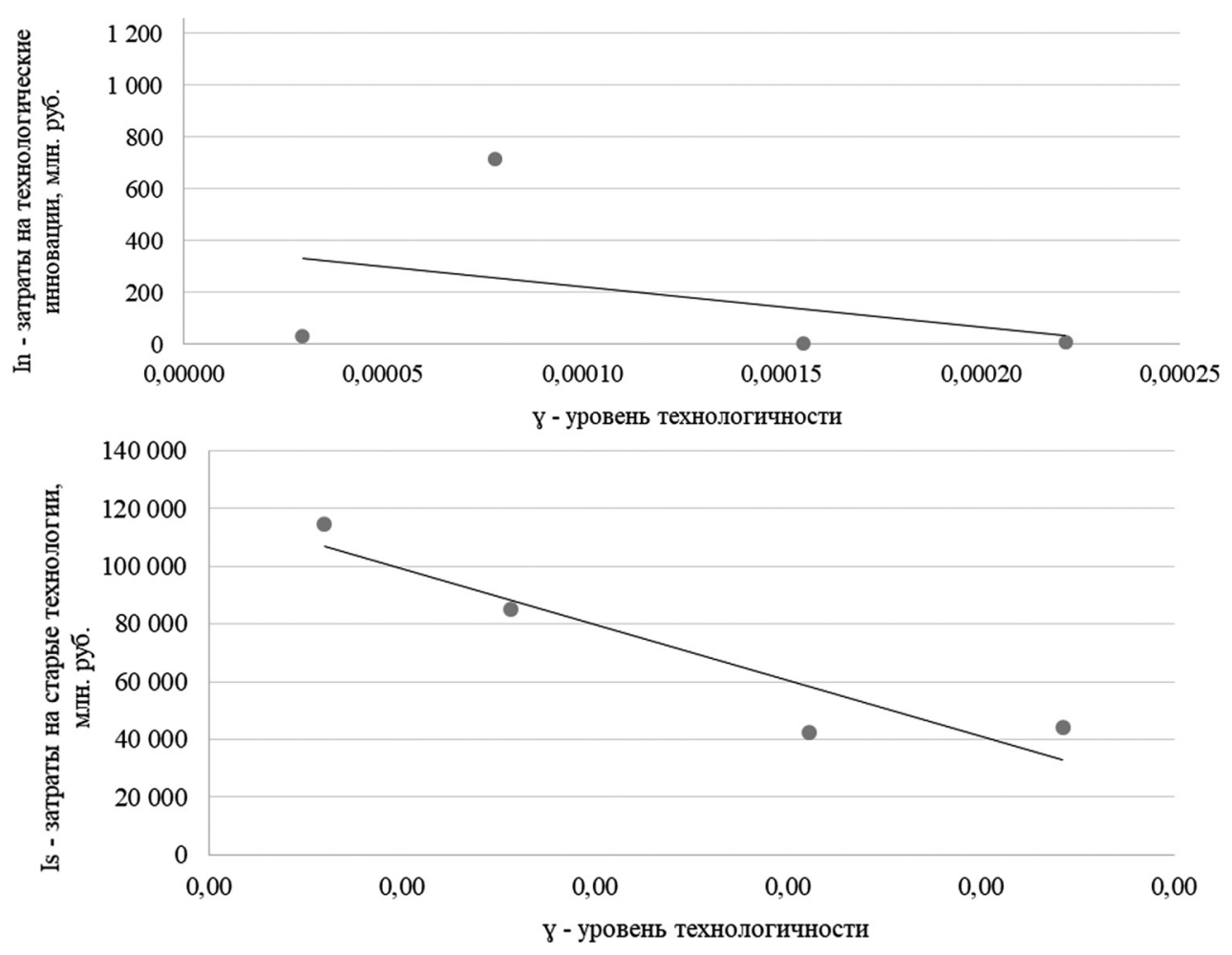

Рис. 9. Зависимость уровня технологичности от затрат на новые (вверху) и старые (внизу) технологии в Ненецком автономном округе, 2010-2016 гг.
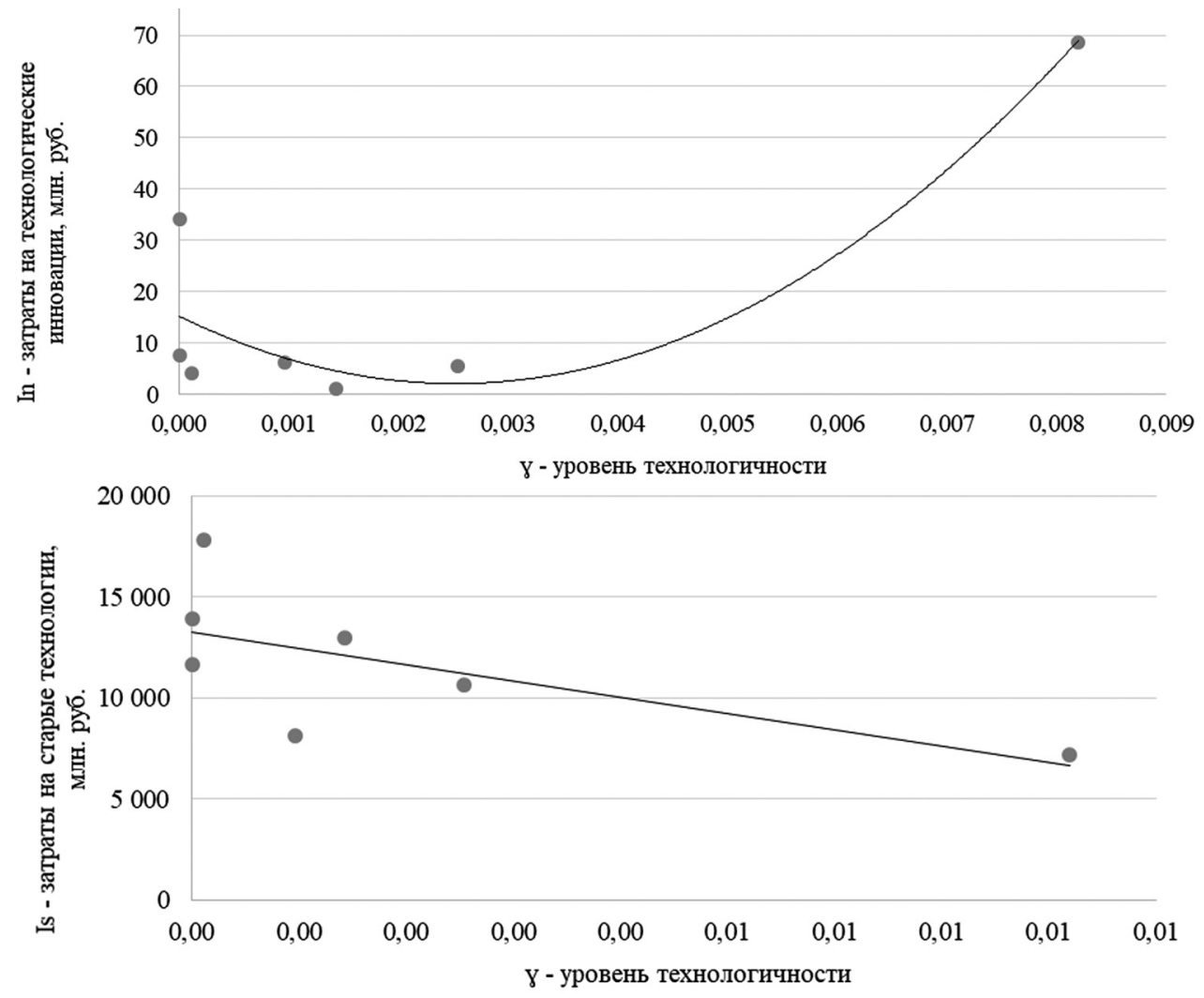

Рис. 10. Зависимость уровня технологичности от затрат на новые технологии в Республике Тыва, 2010-2016 гг. 
Среди регионов-аутсайдеров рейтинга инновационного развития регионов России уровень технологичности выше в Республике Дагестан - среднем за 2010-2016 гг. составляет 0,013, при этом затраты на технологические инновации низкие (ниже только в Республике Тыва). Наибольшие затраты на технологические инновации - среди отстающих инновационных регионов в Ненецком автономном округе.

Так, уровень технологичности выше российского в следующих регионах: Новосибирская область, Республика Татарстан, Нижегородская область, Московская область; уровень технологичности ниже российского отмечается в Томской и Калужской областях, Чукотском и Ненецком автономных округах, Республиках Тыва и Дагестан.

На основе проведенного анализа и с учетом подхода к моделям технологической индустриализации, представленного в табл. 1, проведем ранжирование регионов по реализуемой ими стратегии технологического развития за период 2010-2016 гг. (табл. 2).
Из табл. 2 следует, что регионы, занимающие ведущие позиции в рейтинге инновационного развития, демонстрируют различные стратегии технологического развития, в частности, Томская область - стратегию лидерства, Новосибирская, Нижегородская, Московская и Татарстан - технологического рывка. Такое позиционирование связано с тем, что инвестиции в новые технологии во всех указанных регионах оказывают положительное влияние на технологический уровень, а инвестиции в старые технологии в Томской области снижают технологичность, в отличие от регионов со стратегией технологического рывка.

Для регионов со стратегией «сдача позиций» только инвестиции в старые технологии повышали уровень технологичности. Технологическая деградация свойственна тем регионам, где уровень технологичности не чувствителен к инвестициям в новые и старые технологии.

Поскольку дальнейший анализ с учетом мониторинга процесса индустриализации слишком громоздкий, по всем избранным для
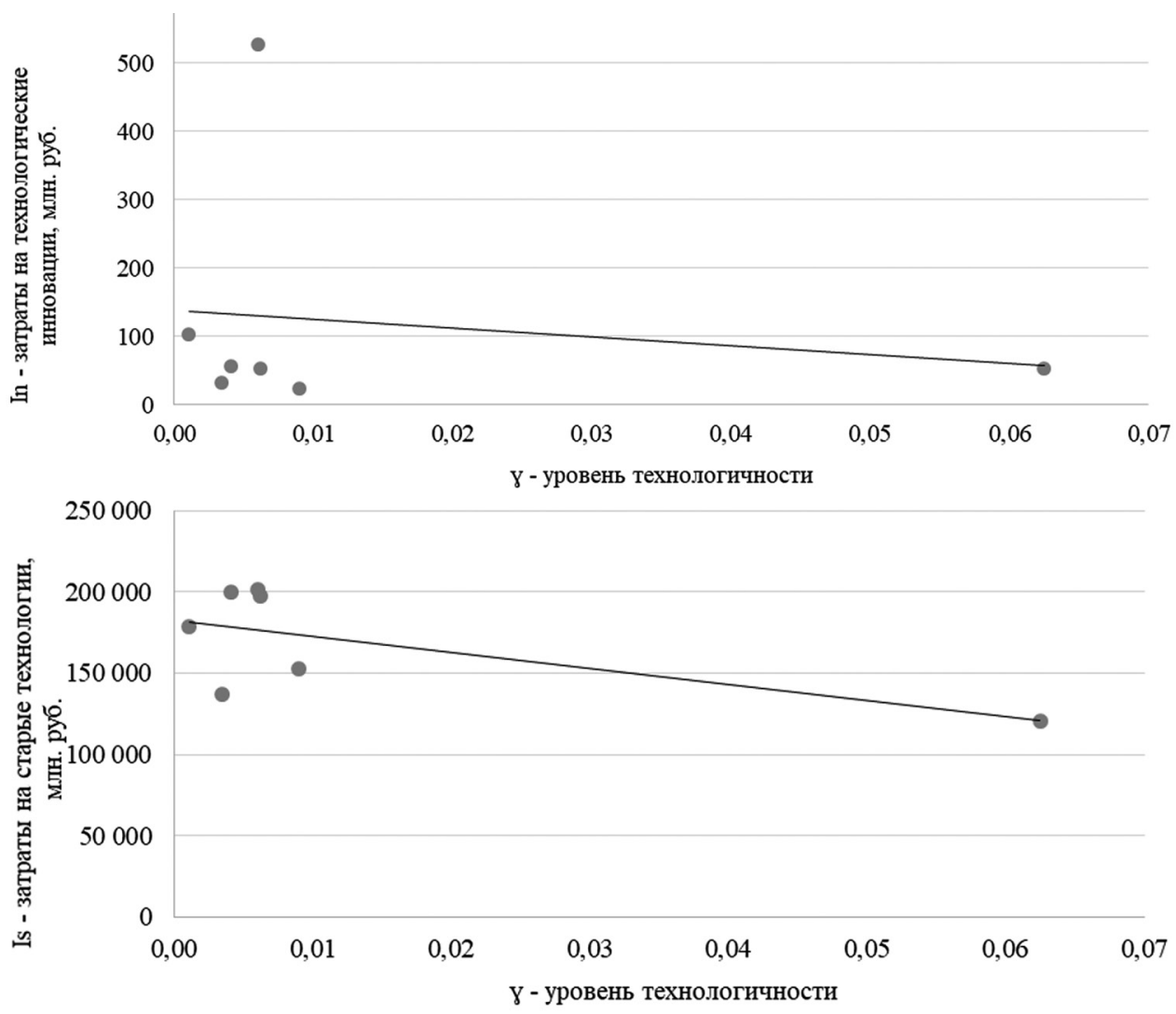

Рис. 11. Зависимость уровня технологичности от затрат на новые (вверху) и старые (внизу) технологии в Республике Дагестан, 2010-2016 гг. 
Таблица 2

Стратегии технологического развития регионов-лидеров и регионов-аутсайдеров рейтинга инновационного развития России

\begin{tabular}{|c|c|}
\hline $\begin{array}{c}\text { «Лидерство» } \\
\text { Томская область }\end{array}$ & $\begin{array}{c}\text { «Сдача позиций» } \\
\text { Калужская область, } \\
\text { Чукотский автономный округ }\end{array}$ \\
\hline $\begin{array}{c}\text { «Технологический рывок» } \\
\text { Новосибирская область, } \\
\text { Республика Татарстан, } \\
\text { Нижегородская область, Московская область }\end{array}$ & $\begin{array}{c}\text { «Технологическая деградация» } \\
\text { Республика Дагетстан, Республика Тыва, } \\
\text { Ненецкий автономный округ }\end{array}$ \\
\hline
\end{tabular}

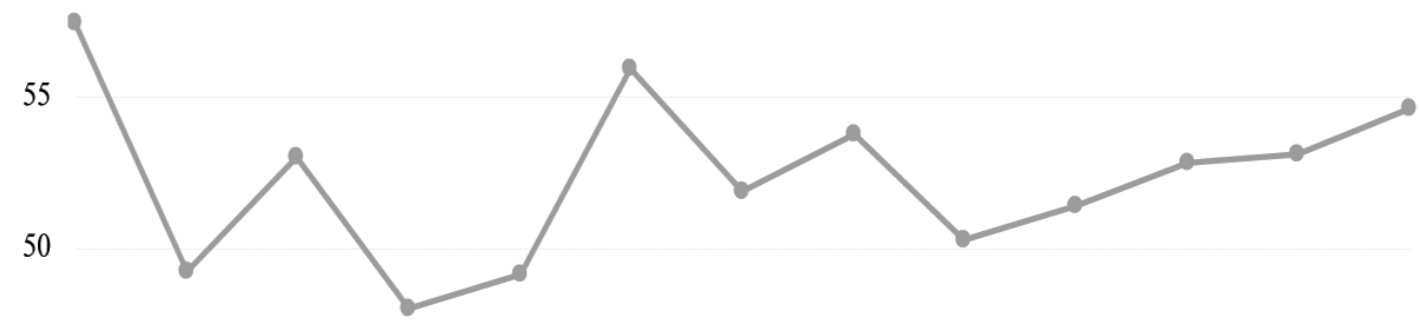

45

40

$\begin{array}{lllllllllllll}2004 & 2005 & 2006 & 2007 & 2008 & 2009 & 2010 & 2011 & 2012 & 2013 & 2014 & 2015 & 2016\end{array}$

$\rightarrow X(\mathrm{t}), \%$

Динамика параметра X(t), \%

0,4

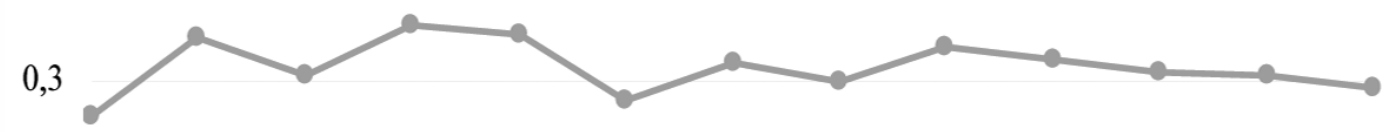

0,2

0,1

0,0

$\begin{array}{lllllllllllll}2004 & 2005 & 2006 & 2007 & 2008 & 2009 & 2010 & 2011 & 2012 & 2013 & 2014 & 2015 & 2016\end{array}$

$$
\text { Динамика параметра K(t), \% }
$$

Рис. 12. Параметры $X(t)$ и $K(t)$ индустриализации для Брянской области, 2004-2016 гг. (обрабатывающий и трансакционно-сырьевой сектора) 


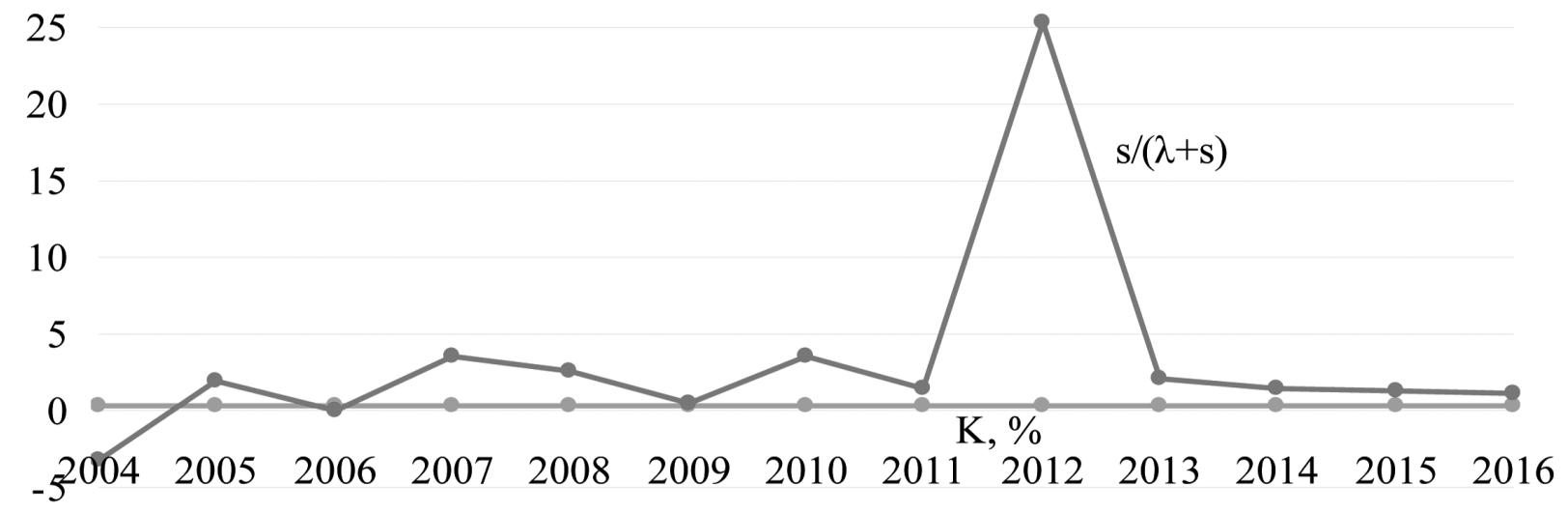

Рис. 13. Общий критерий индустриализации Брянской области, 2004-2016 гг.

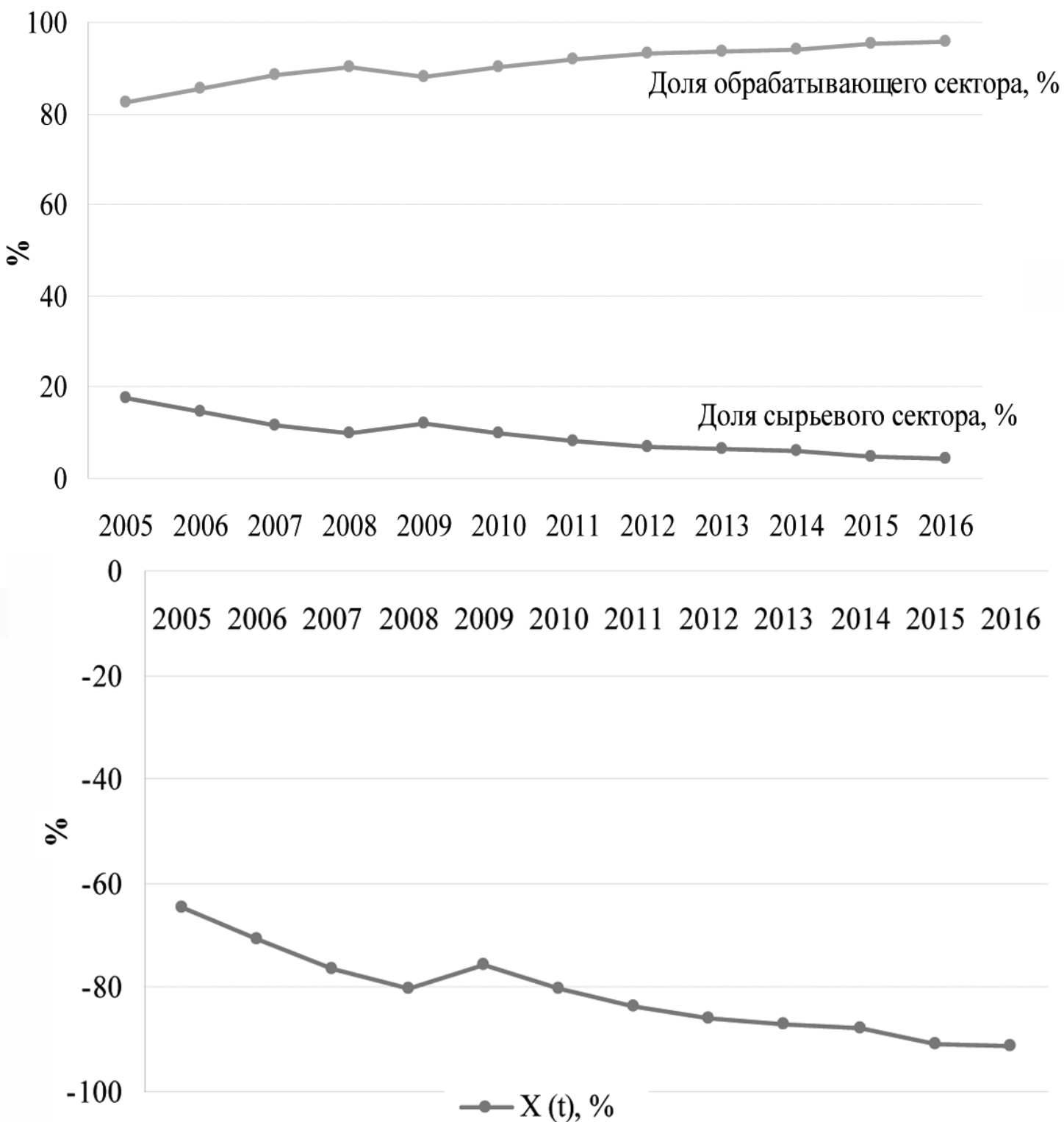

Рис. 14. Структура экономики Брянской области (обрабатывающий - сырьевой сектора, вверху), параметр $X(t)$ (внизу) 
25

20

15

10

5

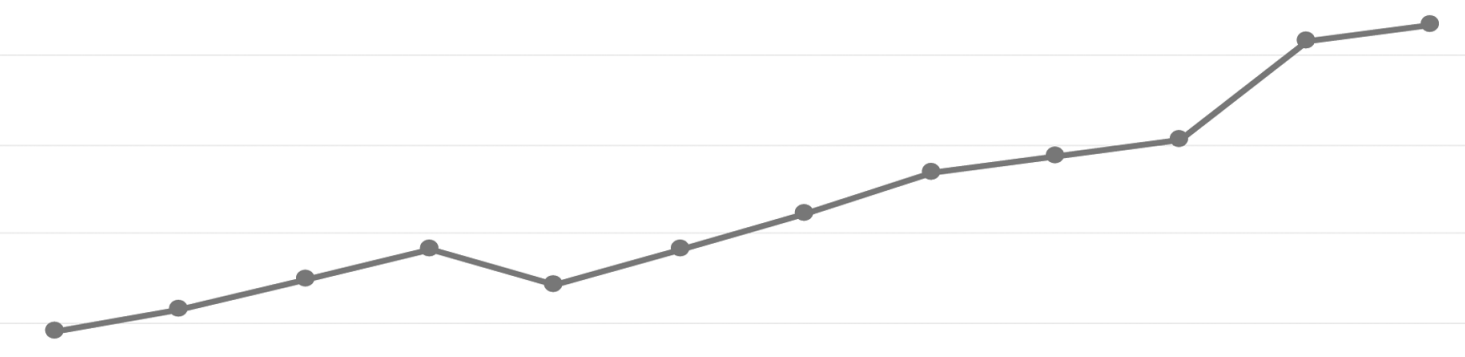

0

200520062007200820092010201120122013201420152016 $\longrightarrow \mathrm{K}$

Рис. 15. Параметр $K$ для Брянской области, 2005-2016 гг.

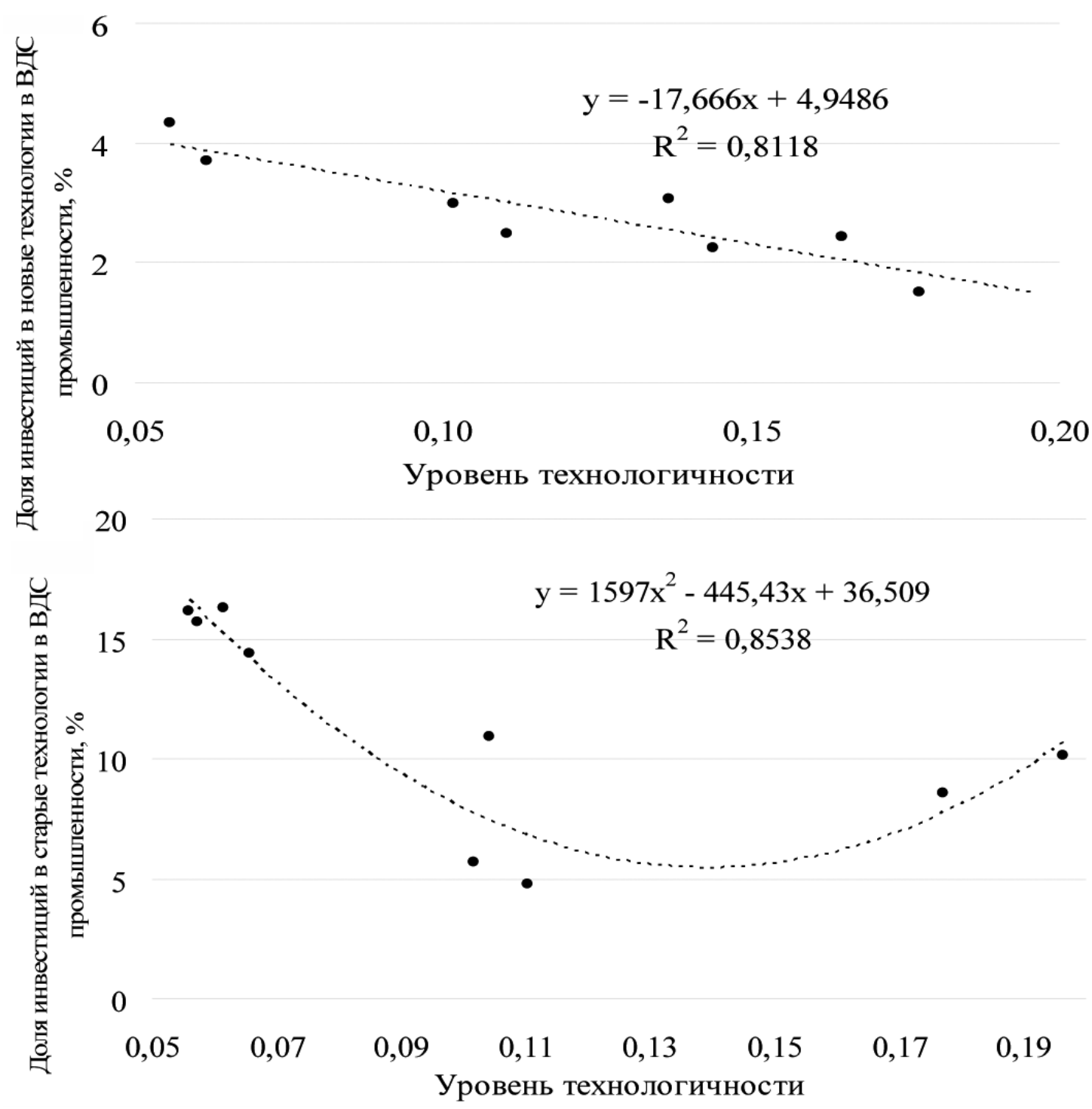

Рис. 16. Инвестиции в новые (вверху) и старые (внизу) технологии в промышленности Брянской области и уровень технологичности 


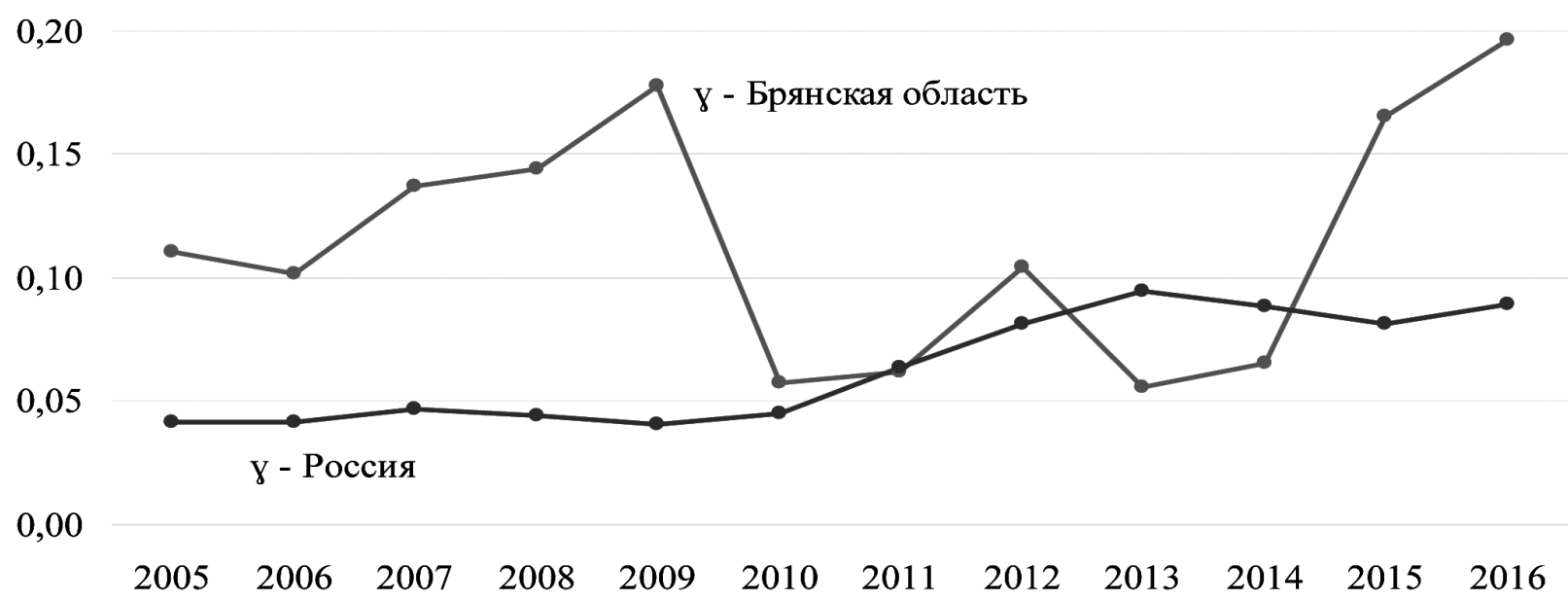

Рис. 17. Технологичность экономики России и Брянской области

(по промышленности), 2005-2016 гг.

рассмотрения регионам проведем его только для Брянской области.

Анализ динамики Брянской области по общему и специальному критериям индустриализации. Рис. 12 отражает экономическую структуру Брянской области.

Поскольку $X(t)>0$ и $K(t)<1$, то имеет место деиндустриальная экономика региона. Причем, параметр $X$ показывает значительные изменения, что характеризует неустойчивость регионального экономического развития.

Критерий индустриализации, предложенный автором в ряде прошлых работ, также подтверждает наличие деиндустриализации для экономики Брянской области (рис. 13). По критерию $K>s /(\lambda+s)$ - должно быть для процесса индустриализации [3].

Анализ инвестиций в новые и старые технологии в промышленности Брянской области (рис. 16) показывает, что рост доли инвестиций в новые технологии сопровождается снижением уровня технологичности системы. По инвестициям в старые технологии определенная динамика не наблюдается: в диапазоне более низкой технологичности $(0,05-0,13)$ рост доли инвестиций в старые технологии понизит уровень технологичности; для более высокой технологичности $(0,15-0,19)$ рост доли инвестиций в старые технологии может повысить уровень технологичности промышленности региона.

Отметим, что величина технологического уровня промышленности Брянской области выше российского уровня технологичнос- ти (за исключением 2011 г., 2013-2014 гг.), который не превышает 0,1 (рис. 17).

Из рисунка 17 видно, что уровень технологичности Брянской области в среднем выше российского уровня. Однако, на рассмотренном интервале времени рост инвестиций в новые технологии сопровождался не повышением, а понижением технологичности, а в старые технологии - имеются два участка, которые говорят как и возможном понижении уровня технологичности, так и о повышении с ростом инвестиций в старые технологии. Тем самым деиндустриальная экономика Брянской области ко всему показывает запирающий режим технологического развития, что ограничивает возможности технологического обновления. Решение проблемы может видеться в системном изменении экономики такого региона, проведения структурной политики [1, 10-11, 14-15], которая бы сводилась не только к неким институциональным коррекциям и реализации отдельных программ (при всей их полезности), но обеспечила бы обрабатывающий сектор необходимыми ресурсами и позволила бы осуществить технологическое обновление экономики региона.

\section{Заключение}

Подводя итог проведенному исследованию, отметим следующие наиболее существенные выводы.

Во-первых, согласно представленному здесь подходу, удается выделить режимы 
технологического развития, учтя исходное состояние индустриального сектора рассматриваемых регионов. Так, экономика региона может демонстрировать процесс индустриализации, однако при этом технологическое обновление тормозится (развитие индустрии на старых технологиях).

Во-вторых, возможны запирающие режимы технологического развития, когда и инвестиции в новые и старые технологии не дают повышения общего технологического уровня региональной экономической системы, в то время как регион характеризуется общей технологичностью выше, нежели средний российский уровень (этот режим показан на примере Брянской области). В таком случае требуется проводить политику интенсификации инвестиций, причем и в старые технологии особенно, но и изменять структуру региональной экономической системы, показывающей такой запирающий режим функционирования. Опасность данного режима - институциональное его закрепление, когда технологическое обновление потребует добавочных ресурсов на преодоление сложившихся отсталых в развитии экономических секторов.

Таким образом, как региональная экономическая политика, так и федеральная составляющая региональной политики в масштабе страны должны учитывать уже сложившиеся модели индустриального и технологического развития. Важны сложившиеся режимы технологического обновления, характеристика которых может быть дана по оценке чувствительности технологического уровня к инвестициям в новые и старые технологии (потому как именно такая дихотомия определяет характер технологического обновления региональной экономики). Далее требуется определить чувствительность иных инструментов воздействий на экономику конкретного региона с тем, чтобы обоснованно формировать политику развития обрабатывающих секторов.

\section{Литература}

1. Доклад НИУ ВШЭ. Структурная политика в России: новые условия и возможная повестка // Вопросы экономики. - 2018. №6. - C. 5-28.
2. Маевский В. И. Введение в эволюционную макроэкономику. - М.: Япония сегодня, 1997. - $108 \mathrm{c}$.

3. Сухарев О.С. Оценка уровня индустриализации региональной экономики и региональная промышленная политика // Экономическая политика и ресурсный потенциал региона: сб. статей всерос. науч.-практ. конф. - Брянск: Брян. гос. инженерно-технол. ун-т. - 2018. - С. 152-163.

4. Сухарев О.С. Региональная экономическая политика: структурный подход и инструменты (теоретическая постановка) // Экономика региона. - 2015. - №2. - С. 9-23.

5. Сухарев О.С. Структурный анализ технологических изменений и стратегия экономического роста // Известия Уральского государственного экономического университета. - 2018. - №3. - С. 26-41.

6. Сухарев О.С. Теория реструктуризации экономики. - М.: Ленанд, 2016. - 256 с.

7. Сухарев О.С. Эмпирические факты к теории реформ и экономического роста // Экономика и предпринимательство. 2017. - №2. - С. 26-37.

8. Сухарев О.С., Ворончихина Е.Н. Стратегия индустриализации экономики. Исследование структуры экономического роста и технологического обновления. - М.: Ленанд, 2019. - $320 \mathrm{c.}$

9. Шумпетер Й. Теория экономического развития. Капитализм, социализм и демократия. - М.: Эксмо, 2007. - 864 с.

10. Яременко Ю.В. Приоритеты структурной политики и опыт реформ. - М.: Наука, 1999. - 414 с.

11. Andergassen R., Nardini F., Ricottilli M. Innovation diffusion, general purpose technologies and economic growth. Structural Change and Economic Dynamics. — 2017. — Vol.40. №9. - P. 72-80.

12. Drucker J., Feser E. Regional industrial structure and agglomeration economies: An analysis of productivity in three manufacturing industries // Regional Science and Urban Economics. - 2012. - Vol. 42, Issues 1-2. - P. 1-14.

13. Romano L., Traù $F$. The nature of industrial development and the speed of structural change. Structural Change and Economic Dynamics. - 2017. - Vol. 42. - P. 26-37.

14. NeriA., Cagno E., Sebastiano G.D., Trianni $A$. Industrial sustainability: Modelling 
drivers and mechanisms with barriers // Journal of Cleaner Production. - 2018. - Vol. 194. P. 452-472.

15. Vu K.M. Structural change and economic growth: Empirical evidence and policy insights from Asian economies // Structural Change and Economic Dynamics. - 2017. — Vol. 41. P. 64-77.

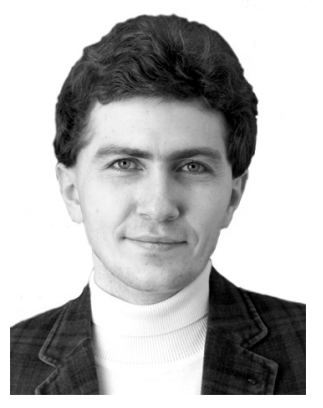

Сухарев Олег Сергеевич - доктор экономических наук, профессор, главный научный сотрудник Института экономики PAH.

Sukharev Oleg Sergeevich - Doctor of Economics, professor, main scientist researcher of Institute of Economics of the Russian Academy of Sciences.

117218 , г. Москва, Нахимовский просп., 32

32 Nakhimovskiy ln., 117218, Moscow, Russia

Тел.: +7 (499) 724-15-41; e-mail: o_sukharev@list.ru

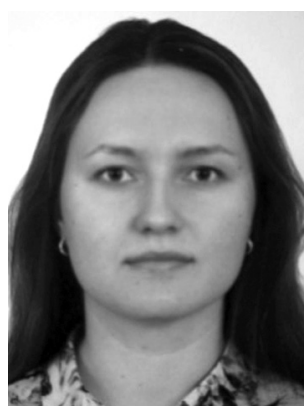

Ворончихина Екатерина Николаевна - ассистент кафедры мировой и региональной экономики, экономической теории Пермского государственного национального исследовательского университета.

Voronchikhina Ekaterina Nikolaevna - assistant of the Department of world and regional Economics, economic theory of Perm state national research University.

614990, г. Пермь, ул. Букирева, 15

15 Bukireva st., 614990, Perm, Russia

Тел.: +7 (902) 479-71-69; e-mail: envoronchikhina@gmail.com 